\title{
The Enlightenment of Taiwan B\&B Tourism Development on Hainan Rural Tourism
}

\author{
Zhang Yu-xiu ${ }^{1, a}$, Chen Tang ${ }^{2, b}$, Wang Jue ${ }^{3, c, *}$ \\ ${ }^{1}$ School of Humanities \& Law, Hainan Radio \& TV University, Haikou, Hainan, China \\ 2 School of Humanities \& Law, Hainan Radio \& TV University, Haikou, Hainan, China \\ ${ }^{3}$ School of International Tourism, Hainan Radio \& TV University, Haikou, Hainan, China \\ akeyanch@163.com, b1164126791@qq.com, c1205356898@qq.com \\ ${ }^{*}$ Corresponding author
}

Keywords: Hainan and Taiwan; comparison; rural tourism; experiences.

\begin{abstract}
Both Hainan and Taiwan attach importance to cultural inheritance and environmental protection during the process of rural tourism development. Hainan can learn from Taiwan in terms of scale, quantity, format, connotation, quality, management concept, etc. To develop rural tourism in Hainan, local conditions should be emphasized and cultural resource characteristics should be highlighted; Furthermore, the government should play a dominant role and operator should play a main role; Hainan should pay attention to diversified development, integration of industries, environmental protection and resource utilization.
\end{abstract}

\section{Introduction}

Cultural eco-tourism is an emerging form of tourism. Zhang Zhujiang (2011) believes that cultural ecotourism combines cultural tourism and ecotourism, which is a comprehensive form of tourism, ideas and tourism products ${ }^{[1]}$. On the whole, cultural eco-tourism integrates eco-tourism and cultural tourism, which enables tourists to enjoy the natural landscape and local culture without destroying the original ecological environment or system, thereby promoting the sustainable development of tourism and realizing the harmony of human, ecological environment and human environment. Therefore, all parts of the China have attached importance to the protection and development of culture and ecology in the tourism development process in recent years, such as Hainan's development in rural tourism.

During the development of the B\&B (bed and breakfast) tourism in Taiwan in the past few decades, the operators have always paid a deep respect for nature and have a deep affection for the culture, which makes the unique charm of Taiwan B\&B tourism. This makes it an important part of Taiwan's rural tourism. The development of Taiwan B\&B tourism, whether it is the type of business, the connotation quality, and the business philosophy, are relatively standardized and mature, which provides valuable experience for the development of rural tourism in Hainan.

\section{Comparison of Taiwanese B\&B Tourism and Hainan Rural Tourism Development}

In 2002, Taiwan joined the WTO, and traditional farming agriculture was hit by high costs. Under such pressure, the government had implemented the transformation of traditional agriculture to leisure agriculture. The Agriculture Committee had fully supported the agricultural areas and the aboriginal areas to carry out agricultural sightseeing tours. Meanwhile, in order to improve the living conditions of the aborigines in the mountains, the government encouraged the aborigines to use the local natural and human resources to convert the free houses into homestays to increase income. As a result, Taiwan's rural tourism industry is booming, and many homestays have emerged in mountainous areas, tea-producing areas and agricultural recreation areas. The benefits of affordable 
tourism, in-depth contact with local residents and enthusiasm for service have promoted the development of local tourism.

The second turning point of Taiwan B\&B occurred in 2001. In the same year, the Tourism Bureau of the Ministry of Communications of Taiwan promulgated the "Budget Management Measures" to rationalize and guide the hotel industry. The Taiwan government also implemented the weekend break system in the same year, so that the people had the leisure time required for tourism, and the tourism bias shifted from sightseeing to leisure. The B\&B had been developed as a bridge for deep contact with Aboriginal people. According to the latest data as of April 2015, Taiwan currently has more than 7,000 legal homestays. Compared with 2010, the number of homestays has increased by more than 4,000 . The total number of guest rooms has increased by more than $70 \%$, and the total number has increased from 15,658 to $26,357^{[2]}$.

In recent years, in order to build a well-off society in an all-round way and improve the living standards of farmers, Hainan Province advocates combining barn development with beautiful rural construction and poverty alleviation. It is suggested to accelerate the construction of infrastructure such as beautiful rural roads and tourist signs and to encourage poor households to participate in the construction and operation of the homestay, so as to enhance the ability to get rid of poverty. At the same time, it is proposed to do a good job in the top-level development of the B\&B and develop and construct the characteristic B\&B. In 2016, Hainan was identified as the country's first global tourism demonstration province. Hainan Province focused on opening up a network from provincial tourist attractions to rural areas and comprehensively developing supporting infrastructure. At the provincial level, the survey of the B\&B industry is also actively carried out ${ }^{[3]}$, which brings new opportunities for rural tourism and development of residential houses. However, Hainan's rural tourism is still in its infancy, which is reflected in the small number of country houses, the relatively junior activities and the weak supporting facilities.

\subsection{Hainan Rural Tourism Poverty Alleviation and Taiwan B\&B Leisure Tour}

Both Hainan and Taiwan adhere to the principles of tourism development tailored to local conditions. "The Hainan Provincial Rural Tourism Master Plan (2014-2020)" proposes that rural tourism refers to tourism product and method in rural areas based on the unique farming culture, human settlements, folk customs, rural scenery and natural background. And it proposes to develop rural tourism claims of "one village, one product" and "one family one art" [4] according to local conditions; The "Three-Year Action Plan for Tourism Poverty Alleviation in Hainan Province" also mentions the development of rural tourism according to local conditions. For example, relying on the experience of poverty alleviation in the tourism of Shihan Village in Qiongzhong, it is necessary to carry out tourism poverty alleviation according to local conditions and develop tourism modes such as agricultural sightseeing and rural vacation; Taiwan's " $B \& B$ Management Measures" defines B\&B as a residential side-run business that provides accommodation for travelers in rural areas ${ }^{[5]}$. It uses its own free-living rooms to combine local humanities, natural landscapes, ecology, environmental resources as well as the production activities of agriculture, forestry, fishing and animal husbandry.

2.1.1 Taiwan's experience of transforming tourism disadvantages into advantages and characteristics

On the east coast of Taiwan, Yilan, Hualien and Taidong have become a leisure and holiday paradise with the unique advantages of backing the central mountain range and facing the Pacific Ocean. In addition, after the initial development, the existing owners of the homestays are mostly young people returning from big cities and even overseas. They have broad vision and rich creativity, and develop diversified tourism products, which makes the tourism of the hotel more refined.

The Taiwan Tourism Bureau held a hotel selection campaign in 2009, and selected 323 "hospitality hotels". More than half of the homeowners have advanced degrees and even overseas study experience. They borrowed the European B\&B model and Japan's B\&B experience and developed it in Taiwan. They registered and marketed on the International Accommodation Enquiry website for foreign visitors who are going to Taiwan, which directly enhanced the influence of 
Taiwan B\&B. The change in the tourist population also promotes the improvement of facilities and facilities in the hotel ${ }^{[6]}$.

Taiwan B\&B is good at discovering local characteristics and making it a unique travel experience. The sound of frogs in the fields near the homestay has become a unique and interesting scene; Taiwan's old English manor is backed by mountains, facing the sea, and water is inconvenient, but the operators are good at turning disadvantages into advantages. Owners use space as much as possible to transform many ordinary underground passages that are abandoned by hotels into high-end, romantic music venues; there are not many hotel entertainment facilities, and the owner defines his own homestay as "a place to empty the mind and body." The advertising aspect focuses on rendering the guests to taste the English afternoon tea, and enjoy the rare and comfortable scenes; The scenery on the mountain is beautiful, and there are classical European architectures. Due to its humid climate, the famous Shifen old street has become the only place in Taiwan that can be used for the skylights. Also, it is the place where the male and female protagonists put the sky lanterns in the movie "You Are the Apple of My Eye", and it is also the place where the Taiwanese people put the sky lanterns and send blessings. "Put sky lanterns in the Shifen old street" has been transformed from a resource advantage to a cultural heritage.

2.1.2 Hainan's practice of using rural local resources to make icing on the cake

Qionghai on the east coast of Hainan is based on local conditions and adheres to the famous viewpoint of "not cutting trees, not demolishing houses, not occupying fields, and urbanizing on the spot". In three or four years, Qionghai has created a famous new tourist attraction in rural areas. For example, the famous Boao pastoral town is transformed into a cafe filled with the smell of fishing villages by using old and old houses. The town renovated the Hainan-style façade of the existing townhouse building and paved a leisurely slow road in the field, so as to allow visitors to enjoy the beauty of the Hainan countryside in the countryside, where the flowers are crowded and the tropical plants are scattered.

In addition, the Nanhai Cultural Town of Tanmen and the Nanyang Style Town of Central Plains use local existing dwellings to carry out rural tourism with the theme of marine culture. In the town, tourists not only appreciate the beautiful pastoral scenery of Hainan, but also taste the characteristic farm food. This rural tour with local characteristics has greatly promoted the development of rural tourism and attracted a group of domestic and foreign tourists who loved the country.

2.1.3 Comparison and gap

Although both Taiwan and Hainan follow the principle of developing rural tourism according to local conditions, Hainan's rural tourism is highly similar. Hainan also emphasizes cultural connotations, but lacks interaction with tourists and the lifestyle project that tourists experience local cultural. Thus, many "cultural towns" and "cultural villages" often only have representations. Hainan should learn from the Taiwan model and impress visitors with the field experience project, and provide visitors with the opportunity to return to the countryside and return to nature. 


\begin{tabular}{|c|c|c|}
\hline Key points & Common points & Taiwan's experience \\
\hline $\begin{array}{l}\text { Adapt to local } \\
\text { conditions }\end{array}$ & $\begin{array}{l}\text { 1. Both have clearly defined } \\
\text { the development according to } \\
\text { local conditions in concept. } \\
2 \text {. Both pay attention to } \\
\text { "adapting to local conditions" } \\
\text { from the perspective of } \\
\text { dislocation competition and } \\
\text { resource conservation in rural } \\
\text { tourism in the region. }\end{array}$ & $\begin{array}{l}\text { 1. Be good at turning disadvantages into resource } \\
\text { advantages } \\
\text { 2. Taiwan model can identify its own positioning } \\
\text { according to the characteristics of local resources, } \\
\text { and develop a target source market accordingly, } \\
\text { thus forming a unique competitive advantage. } \\
\text { 3. The resource advantage is transformed into } \\
\text { cultural heritage }\end{array}$ \\
\hline
\end{tabular}

\subsection{Degree of policy refinement and different levels of participation}

\subsubsection{Different levels of policy refinement}

The governments of both Hainan and Taiwan have adapted to the needs of the rural tourism market and promoted the development of rural tourism. However, in terms of policy formulation, Hainan focuses on planning rural tourism development from the macro level, while Taiwan prefers to introduce specific and feasible special regulations from the micro level. For example, Hainan's "Overall planning of rural tourism in Hainan province (2014-2020)", as a special plan for regional tourism development, guides Hainan's rural tourism planning, construction, management and marketing from a macro perspective; The "Opinions of the Hainan Provincial People's Government on Accelerating the Development of Rural Tourism" and the "Division and Assessment of the Classification of Rural Tourism Points (Districts) in Hainan Province (Trial)" and other documents propose to promote rural tourism construction. Moreover, rural tourism is one of the ten poverty alleviation measures in Hainan. These macro-strategic plans are certainly the program of action. However, Hainan's refinement of rural tourism is relatively rare, which is not conducive to concrete implementation and is not conducive to the development of rural tourism.

In 2001, Taiwan promulgated the "Budget Management Measures", which set clear requirements for the size, facilities, fire protection, registration, responsibility, management and other subtle aspects of the hotel. For example, the number of rooms is generally less than 5 in the unified B\&B; the number of guest rooms is less than 15 in the leisure land, leisure agriculture area, sightseeing area, remote area and outlying island area approved by the aboriginal reserve. A series of special regulations such as the "Administrative Measures for Leisure Agriculture Counseling" and "Key Points for the Examination of Leisure Farm Management Plan" have been issued. The local government of Taiwan assumes the leading responsibility, pays attention to supervision, and makes unified requirements for the business qualifications, facilities standards and service management of the hotel, and issues business licenses. The government limits the size of the hotel to avoid blind expansion and vicious competition. The Taiwan government has also adopted a series of measures such as technology introduction and capital guidance to encourage young people to return home.

\subsubsection{The degree of participation of both is different}

NGOs (non-governmental organizations) have been established in Taiwan and Hainan to promote the development of rural tourism. Taiwan's industry organizations are relatively developed. There are many institutions such as the B\&B Association and the Tourism Quality Assurance Association. They accept consumer complaints, promote the standardized and orderly development of the property industry, and give full play to coordination, guidance, management, service, supervision, training and other functions to achieve a one-stop service. In particular, the Taiwan B\&B Association has played an important role in promoting the government's formal management regulations, and has acted as an industry think tank and encouraged the development of unique local resources to build a special 
homestay. It also guides the owner of the hotel to promote the special food, the surrounding tourism service, the souvenir shop and the leisure facilities from a single accommodation, and promote the scale in the form of a homepage marketing website.

The Hainan Rural Tourism Alliance was established in 2015. It is committed to tapping the potential of Hainan's rural tourism innovation and development, and exerting synergies to achieve interconnected, mutually beneficial, shared resources, common development, and expanding the source market. However, Hainan currently adopts a rural tourism development model of "government-led, cooperative cooperation between enterprises and rural cooperatives, participation of farmers in stocks", "enterprise + farmers", "companies + cooperatives + farmers". Although the proportion of market participation is increasing day by day, some farmers still wait for government support and foreign capital investment. After the project is developed, farmers still lack the initiative to develop awareness and the corresponding business philosophy. Taiwan also relies on government, enterprises, farmers, and NGOs to promote it. However, Taiwan's rural tourism projects are generally funded by local farmers and developed through associations, farmers' associations and farmer cooperatives. The goal of government support and farmers' active development of rural tourism is clear and consistent: it is to increase farmers' income. Taiwan Hengchun Ecological Farm operators feel that the ideal agriculture is not only "The sunrise makes, the sunset but the rest. ", but more importantly, "let the people make money on the land and find dignity."

\subsubsection{Reference and comparison}

Taiwan's policies are more detailed and more enforceable. The government has a greater role and participation, and its business philosophy is more advanced and its means are more innovative. For example, the Taiwanese government stipulates that primary and secondary school students should go to the government-designated environmental education bases such as Fei Niu Farm to receive relevant education and purchase "public accident insurance". The travel agency is the main body responsible for and protecting the safety of the students during the farm. In addition, Taiwanese homestay owners and visitors are more interactive. Some enjoy music with the guests; some take guests with low-carbon rides to swim in the village; some take guests down to understand the frog habits; some protect the guests across the mountains and gullies; some accompany the guests to watch the fireflies and enjoy the moon Some teach guests DIY baking and so on. While the host and guest experience the local cultural ecology together, it also further enhances the emotional exchange.

\begin{tabular}{|c|c|c|}
\hline Key point & Common points & Taiwan's experience \\
\hline $\begin{array}{l}\text { The role of } \\
\text { the two } \\
\text { governments }\end{array}$ & $\begin{array}{l}\text { 1. Both are in line with the needs } \\
\text { of the rural tourism market and } \\
\text { actively promote the development } \\
\text { of rural tourism. } \\
\text { 2. Both have issued policies that } \\
\text { are in line with local conditions. } \\
\text { 3. Both are promoted by means of } \\
\text { financial subsidies } \\
\text { 4. The government's support and } \\
\text { farmers' initiative to develop rural } \\
\text { tourism is clearly aimed at } \\
\text { increasing farmers' income. } \\
\text { 5. Both have industry } \\
\text { organizations, and companies can } \\
\text { cooperate with each other. }\end{array}$ & $\begin{array}{l}\text { 1. Taiwan's policies are more detailed and more } \\
\text { enforceable. } \\
\text { 2.Taiwan limits the scale, business } \\
\text { qualifications, facilities standards, service } \\
\text { management standards, etc. of B\&Bs, to avoid } \\
\text { blind expansion, vicious competition, thereby } \\
\text { making services and management more } \\
\text { standardized } \\
\text { 3. It is encouraged young people to return home } \\
\text { to contribute. } \\
\text { 4. NGOs have sound development, complete } \\
\text { functions, wide coverage, and the right to } \\
\text { speak. } \\
\text { 5. All parties in Taiwan have a greater role to } \\
\text { play. } \\
6 \text {. The farmer's initiative is stronger, the } \\
\text { business philosophy is more advanced, the } \\
\text { means are more innovative, and the owner of } \\
\text { the hotel has a stronger sense of active } \\
\text { development and attaches importance } \\
\text { interacting with the guests. }\end{array}$ \\
\hline
\end{tabular}




\subsection{Comparison of diversified development and multi-industry integration}

"Overall planning of rural tourism in Hainan province (2014-2020)" proposes that rural tourism meets the needs of residents for sightseeing, experience, leisure, vacation, etc. Rural tourism is divided into types of scenic spots (lines), resource characteristics, urban suburbs, and excellent environment, ancient village, characteristic industry and so on. Hainan pays attention to diversified and multi-industry integration and develops rural tourism, such as Baishan green tea tourism, Changjiang mango festival, and Fushan coffee style town. However, these rural tourism activities have no distinctive features and fewer tourists. Hainan's tourism and shopping products are single, poor, low in value and low in reputation. Common coconut products and coffee products are difficult to meet the shopping needs of tourists, which is not conducive to promoting the consumption of tourists. In addition, there are 440 rural tourism resources in Hainan Province ${ }^{[8]}$, but the characteristics and positioning of resources are not completely clear, which is not conducive to the diversified development of rural tourism.

The rural tourism spots in Taiwan are clearly classified, the resources are clear, the main business is outstanding, and the characteristics are distinct. By of 2014, there were more than 3,700 rural tourism spots, including 1,244 leisure farms, 1,856 homestays, more than 300 leisure agriculture and fishery parks, and 385 sightseeing orchards ${ }^{[9]}$. Taiwan's rural tourism is integrated with agricultural production, peasant life, rural tourism, production and management, and leisure and holiday. Furthermore, Taiwan is striving to create tourism and shopping brand-name products, such as Alishan Tea, Chishang Rice, Taidong lychee, Pingdong wax apple. These have become the favorite gift for Chinese and foreign tourists, which fully meets the diverse needs of tourists. Taiwan rural tourism develops experiential rural tourism products: For example, a rural tourism operator gets along with frogs and knows the habits of frogs. He often takes guests to the front of the frog cave to tell the guests how to observe the frogs and "make friends" with the frogs; The operators of the village house in Pulai Town, Nantou, invite local experts and growers to teach the guests how to plant the white bamboo shoots. The guests are happy to try the planting in the underground field, return to the pastoral ecological culture and master relevant knowledge during the play; The extended industrial chain such as Fei Niu Farm and Zhaofeng Farm integrates the first, second and third industries and extends from the primary industry to the tertiary industry. In addition to animal husbandry, the farm also offers camping, accommodation, specialty dining, hiking, cycling and other tourism activities. The farm carries out in-depth processing of self-produced dairy products and strict production processes. In order to ensure product quality, the farm has joined relevant international certifications, and many products have been exported to Southeast Asia and other regions, which has virtually increased the international reputation of the farm; Miaoli Nectar Leisure Farm extracts essential oils from plants and sells them to tourists according to different functions, which increases tourists' secondary consumption opportunities; Taiwan's Nantou specialty white bamboo shoots, commonly known as "beauty legs", is a famous Nantou specialty. Therefore, Nantou holds the annual "Beauty Leg Princess" selection event of the annual white bamboo shoot festival. The champion will be hired as the spokesperson of Nantou white bamboo shoots and Puli agricultural products.

What is impressive is the grafting of leisure agriculture and education in Taiwan. Fei Niu Farm is the first environmental education base certified by Taiwan's environmental protection department. Its position is "Nature, Health, and Joy". Children receive relevant education here. After returning home, they still have unfinished feelings. They often ask their families to visit the education base again. According to its operators, it not only achieves educational goals, but also wins repeat customers and achieves the dual purpose of profitability through a series of experience activities for children.

It can be seen that Hainan has focused on the development of rural tourism through diversified and multi-industry integration. However, the characteristics of tourism resources in Taiwan are clearer, the industrial chain is more extensive, and more emphasis is placed on mutual benefit and win-win between social and economic benefits. 


\begin{tabular}{|l|l|l|}
\hline Key points & Common points & Taiwan's experience \\
\hline diversified & 1. The government pays & 1.Taiwan has a clear classification, clear \\
development & attention to the diversified & resource characteristics, outstanding main \\
and & development and & business and distinctive features; \\
multi-industry & multi-industry integration & 2. Taiwan fully meets the needs of all aspects of \\
integration & 2. Regional resources have & tourists \\
& their own characteristics, & 3. Taiwan extends its industrial chain, \\
thu forming different & deep-processes tourism products, and attaches \\
& tourism products. & importance the quality of tourism products. \\
& $\begin{array}{l}\text { 3. The two have lengthened } \\
\text { the tourism industry chain } \\
\text { and improved the } \\
\text { comprehensive benefits. }\end{array}$ & $\begin{array}{l}\text { Therefore, tourism products have a great } \\
\text { influence at home and abroad. } \\
\text { 4. Taiwan promotes county and product image } \\
\text { through rural tourism festivals } \\
\text { 5.Tourism and education connects to achieve } \\
\text { social benefits and economic benefits }\end{array}$ \\
\hline
\end{tabular}

\subsection{Comparison between environmental protection awareness and resource utilization rate}

2.4.1. Hainan's awareness of environmental protection is not as good as Taiwan

Hainan has long noticed the importance of ecological protection. In 1998, it first proposed the construction of "ecological province" in the country; in 2011, it launched the "greening island" construction project; in 2012, it proposed the green development strategy; in 2017, the seventh party congress of Hainan Province once again emphasized "unswervingly implementing the strategy of ecological provinces". "Opinions of the Hainan Provincial People's Government on Accelerating the Development of Rural Tourism" (Qiong [2013] No. 67) puts forward the principle of "adhering to local conditions and protecting environmental resources." It strictly implements the environmental assessment system and clarifies environmental protection measures to achieve harmonious development between man and nature, and organic integration of rural tourism development and civilized ecological village construction to ensure the sustainable development of rural tourism. However, Hainan's environmental protection has not yet reached the hearts of the people, and some acts that damage the environment still exist. Some of the coasts have been invaded by large-scale real estate and hotel projects, the quality of sea water has declined, and the marine ecological environment has been damaged.

In Taiwan, official personnel are required to receive at least four hours of environmental protection education at a government-designated base such as Hengchun Ecological Farm to enhance their overall environmental awareness. After the land was acquired by Zhaofeng Farm, it was not eager to develop and cultivated soil for 20 years. After that, resources were "out of nothing" and "activated agricultural land", making the land more fertile and producing better crop quality; Zhaofeng Farm also developed natural resources - "Tan Hot Springs" obtained the first hot spring certification in Taiwan. Besides, it covered "wooden houses" to make land use more complete; Fei Niu Farm adhered to the concept of ecology, production and life, and people live in harmony with nature. There was the first "green store" in the area, which strictly controlled the product processing process through HACCP, and the low-carbon food was self-produced and sold in the store.

\subsubsection{Taiwan pays more attention to functional improvement in resource reuse}

Hainan rural tourism focuses on resource reuse. For example, Hainan Rainforest Old House is a forest tourism resort that integrates Li Miao style and forest industry culture after being designed and reconstructed on the basis of the old houses and old factories of the bluestone structure in the 1960s and 1970s. This fully reflects the concept of energy conservation and environmental protection; Qinghai's "Sea Story" cafe uses fishermen's abandoned fishing boats, fishing nets, and buckets to create a marine culture that creates a timeless style.

Taiwan has outstanding functions in the development and utilization of waste resources. For example, the old factory buildings, warehouse areas and railroad tracks have been transformed into local famous cultural and tourist attractions--the Bo'er Art Zone, which has a small humanistic history museum for education and a small train for children's entertainment. Small sculptures of 
various shapes attract the attention of tourists. The Bo'er Art Zone also often holds unique exhibitions, sculpture exhibitions and concerts. The park is suitable for leisure, tourism and off-campus teaching. It is a new sightseeing attraction full of cultural knowledge and a unique open space for offshore art. Miaoli's Nectar Leisure Farm B\&B uses air-dried melons to make lampshades, and uses discarded wood as the front desk. It is simple and environmentally friendly; the Flying Cow Farm meeting room is made up of waste cowsheds. In addition, some restaurant kitchen garbage has been treated and turned into fertilizer for free to raise flowers for the residents and feed the pigs.

\begin{tabular}{|c|c|c|}
\hline Key points & Common points & Taiwan's experience \\
\hline $\begin{array}{l}\text { Environmental } \\
\text { protection and } \\
\text { resource } \\
\text { utilization }\end{array}$ & $\begin{array}{l}\text { 1.Both pay attention to } \\
\text { environmental protection } \\
\text { 2. Resource reuse }\end{array}$ & $\begin{array}{l}\text { 1. Taiwan is not eager to develop, first do a good } \\
\text { job in resources and environmental protection } \\
\text { 2. When resources are reused, Taiwan attaches } \\
\text { importance perfect functions and highlights } \\
\text { cultural intellectuality. }\end{array}$ \\
\hline
\end{tabular}

\subsection{Comparison between tourism facilities construction and functional matching}

Hainan issued the "Outline for the Construction and Development of Hainan International Tourism Island", which proposed the construction of coastal sightseeing roads to improve the accessibility of scenic spots. In August 2010, Hainan Province and the Ministry of Transport signed the "Summary of Talks on Accelerating the Development of Hainan International Tourism Island Transportation", which clearly established a number of tourist roads with complete facilities, complete functions and meeting international service standards so as to build a coastal road with outstanding features. The rural tourist spots such as Bajiao Village in Baishabang Town completed the construction of tourism infrastructure such as gates, village roads and village road lighting, parking lot construction, country inns, hiking trails, and tourist public toilets. Bajiao Village has thus won the honor of "Hainan Xiaokang Environmental Demonstration Village" and "China's Most Beautiful Leisure Village". Some rural tourist spots in Hainan, such as "Color Bridge Memory", have good tourism resources, but the construction of infrastructure such as transportation is lagging behind, which reduces the accessibility of resources. In addition, Hainan Rural Tourism B\&B is less, and the rare B\&B is also a small room, and the room facilities are not thoughtful and comfortable.

Taiwan has good infrastructure and convenient transportation. Even remote towns and farms, farms, forest farms and tea gardens in the mountains are also accessible, convenient, with complete water and power management networks, perfect parking lots, and free wireless coverage for attractions, hotels and restaurants. Therefore, Taiwan's resources are accessible, and even remote villages can attract customers. The operators of Zhaofeng Farm believe that the place where traffic can be reached is the place where tourism develops. Meanwhile, the room facilities in Taiwan's various homestays are very user-friendly. The rooms and bathrooms are very large. The beds are generally around 1.8-2 meters, and the bed spacing is large, which ensures the comfort of the guests.

\begin{tabular}{|c|c|c|}
\hline Key points & Common points & Taiwan's experience \\
\hline $\begin{array}{l}\text { tourism } \\
\text { facilities and } \\
\text { functional } \\
\text { matching }\end{array}$ & $\begin{array}{l}\text { 1. Both focus on improving } \\
\text { tourism facilities } \\
\text { 2. Both of them improve the } \\
\text { functions of food, lodging, } \\
\text { travel, entertainment, etc. }\end{array}$ & $\begin{array}{l}\text { 1. Taiwan has good infrastructure and } \\
\text { convenient transportation. } \\
\text { 2. Taiwan B\&B facilities are large and } \\
\text { comfortable. }\end{array}$ \\
\hline
\end{tabular}

\subsection{Comparison between cultural resources mining and creativity}

2.6.1. Excavation, inheritance and publicity of cultural resources

Hainan attaches great importance to the inheritance of cultural resources. For example, in order to promote the protection of the intangible cultural heritage of the Li people, Linglong, Changjiang, Baisha and other places have held "Li Jin production craft training courses"; Some Li villages in Hainan have also undergone some transformation on the existing basis, which shows that Hainan has 
made some efforts in protecting intangible cultural heritage. Hainan also used film and television culture to promote mountains and water. For example, due to the filming of the "If You Are the One", Shimei Bay Ai mei hotel has a reputation, thereby many tourists coming to visit.

However, Hainan's propaganda of Li Jin's art is far from enough. Although some Li villages have undergone an overall transformation and the environment has changed greatly, the style has been completely unified. The villas are all in the same style, lacking in character and creativity. The boat-shaped house built by the Li people with coconut leaves, bamboo, thatch and sunflower leaves, which is warm in winter and cool in summer. Meanwhile, the house is comfortable and ecologically friendly, but it has almost disappeared.

Taiwan attaches importance preserving cultural relics. For example, Jiufen Town retains a large number of old-style buildings, and later became one of the prototypes of Hayao Miyazaki's animated film "Spirited Away", and became one of the publicity hotspots;

Taiwanese actor Chen Yanxi made the "Romantic is a feeling" of Fei Niu Farm into a film and television work, and promoted the rural tourism culture image with the help of film and television works and stars. Kenting B\&B is exquisite and unique, with rich themes and different forms, without vicious competition. The $\mathrm{B} \& \mathrm{~B}$ is clean and tidy, small and exquisite, forming a variety of styles of $\mathrm{B} \& \mathrm{~B}$ culture, which is infiltrated by the owner's clever ideas; at the same time, the hotel highlights the cultural atmosphere of regional characteristics. Visitors enjoy the sea and mountains in the room and feel the romance and warmth of the Kenting people.

\subsubsection{Creative design aspects of rural tourism products}

Hainan attaches importance the creation of tourism products. In 2016, the tourism product innovation and creative design competition was launched to stimulate the enthusiasm of relevant personnel. Taiwan focuses on creativity and attention to detail in the development of tourism products. The souvenir of an ecological leisure farm is a seemingly ordinary pen, but the introduction of the scenic area is ingeniously "hidden" in it. This little idea is very interesting and plays a very good publicity role. The door of the Shifen B\&B in SIcheng is taken locally. The raw material is the local coconut shell, which is exquisite and distinctive. Its souvenir is a miniature version of the sky lantern model, printed with the owner's greetings, and has a strong local culture. Souvenirs are small and exquisite and easy to carry. The operators of Fei Niu Farm believe that the development is inseparable from 3D: Design, Development, Drive. Learning is important, but the most important thing is not completely copying, but its own innovation and creativity. It can be seen that Taiwan B\&B is more adept at tapping local cultural resources, paying more attention to tourism product promotion, and the homestay creativity is more distinctive and ingenious.

\begin{tabular}{|l|l|l|}
\hline Key points & Common points & Taiwan's experience \\
\hline $\begin{array}{l}\text { Cultural mining, } \\
\text { inheritance, } \\
\text { publicity and } \\
\text { creative design }\end{array}$ & $\begin{array}{l}\text { Both focus on cultural } \\
\text { heritage and creative design }\end{array}$ & $\begin{array}{l}\text { 1. Taiwan promotes through famous film and } \\
\text { television works } \\
\text { 2. The souvenir design is unique and has a } \\
\text { publicity effect. } \\
\end{array}$ \\
& $\begin{array}{l}\text { 3. Raw materials are locally and creative } \\
\text { 4. The same area of the B\&B has its own } \\
\text { characteristics and has great originality. } \\
\text { 5. Taiwan is good at exploring cultural } \\
\text { resources }\end{array}$ \\
\hline
\end{tabular}

\section{The development strategy of Hainan rural tourism that learn from the Taiwan's experience}

Hainan's rural tourism development has many unique advantages and development opportunities. It should not be copied when borrowing from Taiwan's experience, but should be combined with its own development conditions and advantages. 


\subsection{It is suggested to adapt to local conditions and highlighting the characteristics of cultural resources}

3.1.1. Cultural resources are the root of rural tourism. To develop rural tourism in Hainan, we must highlight the advantages of humanities and tourism resources in various parts of the province

We must make a SWOT analysis of resources and development prospects to understand our own strengths and weaknesses, and from external opportunities and challenges. According to the characteristics of local resources, we can identify our own positioning and develop the target source market accordingly. For example, in Luojing Village, a thousand-year-old village in Hainan, its houses are built with volcanic rock, which is warm in winter and cool in summer, and the villagers do not need air conditioning. It can be used to create a natural and original ecological homestay. Coupled with the rich cultural heritage of the village, and fully tapping and integrating its resource advantages, it can be packaged and launched into rural tourism products, which will surely be favored and favored by the industry. Besides, to avoid the similar development of rural tourism, we can learn from the Kenting B\&B's experience of "one household has one scene and one special feature".

3.1.2. It is suggested to learn from Taiwan's experience on turning disadvantages into resource advantages and transforming advantages into cultural heritage, thus forming unique competitive advantage

Some villages have not rich cultural and tourism resources, and they can take a different approach, such as highlighting their original ecology, natural resources and simple folk customs. Furthermore, it highlights its "fresh air, passionate grandmother, clean village road, frogs in the field" to form a unique "hospital culture" of natural ecology.

\subsubsection{Be good at exploring special resources}

Director General Chen Jukai of Nantou County B\&B Tourism Association talked about a detail of his visit to Guizhou. He started with a common food stall that was ignored by the locals, went deep into the people's homes, and even found antiques, and these cultural heritages that he regarded as treasures turned out to be the daily tools of the food stall operators. Hainan operators should have the unique vision of mining characteristic human resources, fully protect them, and make good use of resources.

\subsection{The government leads and plays a relevant role}

\subsubsection{The role of government-led}

The government continues to maintain a strong posture and gradually increase support for rural tourism; the government should encourage peasants who have achieved success abroad to return to their hometowns to create a new world of rural tourism; the government should improve policies and refine policies so that rural tourism policies are more specific, feasible and operational; the government should improve the supporting infrastructure for rural areas and the tourism facilities needed to develop rural areas. In particular, attention should be paid to improving the accessibility of resources; the government should increase training in ecological protection, safety and health, management and quality of employees; the government should guide the rural planning and functional division to avoid the inconvenience of the guests and the inconsistency. In addition, the government should publicize through various channels to enhance the local villagers' sense of identity and pride in local culture, and cultivate the correct attitude and tourism awareness of the villagers. The government should educate the business households to establish the correct tourism service concept, legally manage the tourism market, and improve the cultural quality of the household; While absorbing the essence of foreign cultures to abandon its dross, the government should control and eliminate the artificially created "indigenous culture" to ensure the healthy and sustainable development of rural tourism.

\subsubsection{The full play of the main role of the operator}

The government should introduce relevant measures to encourage operators to take the initiative to provide quality services to tourists. In Taiwan, the owner of the hotel provides customers with a complete service such as pick-up and drop-off, route arrangement, tour guide explanation, event planning, etc., thereby doing the host warmly and cordially ${ }^{[10]}$. Visitors live with their owners, 
integrate into the local life, and learn about different cultures. Hainan should increase its training for operators, enhance its initiative, aesthetic taste, service awareness, and management level, and promote operators to create a unique, original cultural atmosphere and strong humanistic care and warm feelings of the home; The government should encourage rural tourism operators to personally communicate and interact with customers to provide "friendly functions" that are different from ordinary hotels.

\subsubsection{The full play of the Rural Tourism Association's functions}

The Rural Tourism Association publicizes and implements the national guidelines and policies for promoting the development of rural tourism and leisure agriculture. It also safeguards the legitimate rights and interests of member units and the reputation of the industry, and safeguards the overall interests of the industry; The association should organize foreign exchanges, increase foreign cooperation, and build a bridge between the government departments and other relevant units and the rural tourism industry; The association should also establish its official website to carry out consultation and publicity services, so as to increase publicity and display the membership image, and promote the overall image of Hainan rural tourism.

\subsection{Multi-industry integration development and the innovation of publicity marketing mode}

\subsubsection{Defining the characteristics of Hainan rural tourism resources}

The classification, promotion and image positioning enable the operators to highlight the main business with distinctive features. For example, Haikou He tang Impression Leisure Farm is positioned as "Lotus": enjoy lotus s, lotus tea, eat lotus banquet, pick lotus roots, etc.

\subsubsection{The creation of rural agricultural product brand image}

It is recommended to introduce scientific and technological strength, expand capital investment channels, and carry out deep processing of agricultural product and of good quality. It is recommended to do a good job of product appearance image packaging, to avoid rural tourism souvenirs become synonymous with inferior products. For example, the two towers of Chengmai Meilang are the ancient towers of the Yuan Dynasty. It is one of the four great monuments in Hainan and has a profound history. The main product of Meilang Village is lotus tea. The taste and nutritional value of tea are good, but the brand has not yet been formed. The appearance and image packaging of the products are also general, and the production system and marketing channels are not mature. Similar products in the formation of the brand need to enhance the characteristics and quality, drawing on the experience of Qiongzhong Green Orange, Xinglong Coffee, Fushan Coffee, Baisha Green Tea, Wenchang Chicken, Chengmai Kuding Tea, Hele Crab, Hainan Salt, Ding'an Rice, Danzhou zongzi, Tun Chang black pig and Lingshui Cherry Tomatoes etc, so as to apply for GI product protection.

\subsubsection{Expansion of the industrial chain}

It is recommended to fully meet the diversified needs of the guests for food and shelter, travel, entertainment and education, and to do special and deep job in various elements, especially in special accommodation, special entertainment, special shopping, special travel, and special education. Meanwhile, it is recommended to integrate into the ideas of business (village conference base), raising (village health, pension, nourishing, physical fitness), learning (village examination, development training, photography, collecting wind, camping activities, etc.), leisure (country leisure), emotion (emotional tourism, interaction between operators and tourists, communication with heart), odd (village exploration, exploration, exploration, amusement, novelty experience, etc.) ,which proposed by the Director of the National Tourism Administration Li Jinzao so as to enhance the comprehensive benefits of rural tourism. Meanwhile, it is recommended to learn from Taiwan's experience and focus on details and innovation, design exquisite and distinctive souvenirs in the production chain of the industry chain; when marketing, hold the group to warm up, and use the government, enterprises, rural tourism associations and other NGOs to expand the market. When marketing externally, it is recommended to cooperate with each other and expand the market with NGOs such as government, enterprises, and rural tourism associations. 


\subsubsection{Adoption of experiential marketing methods}

It is recommended to establish a rural tourism experience marketing center to allow visitors to participate in and experience the rural life and production process. For example, tourists live in bed and breakfast, eat farmhouse rice, learn to cook farmhouse food, DIY flower arrangement, pick fruit and vegetables, and feel the nostalgia; or let the tourists listen to the agricultural experts to talk about planting knowledge, and experience the transplanting and farming activities in person, which makes them resonate with the original ecological life of the village while satisfying the products.

3.3.5. Propaganda by famous film and television works

In fact, there are many related film and television works taken in the background of Hainan, such as "The Red Detachment of Women", "End of the world blood", "The Island without Winter", "The Liberation of Hainan Island", "Mrs. Xian". There are also many film and television stars who choose Hainan as a wedding destination. Hainan can use the film and television works and the star effect to promote the overall Hainan rural tourism image.

3.3.6. Promotion of product image through Hainan festival activities and exhibition activities.

It is recommended to use the festive festival, Sanyuesan Festival or local festivals to promote. For example, Chengmai Rural Tourism can use the Coffee Culture Festival; Baoting County can use the Songkran Festival; Changjiang County can use the Mango Festival to promote; At the same time, it is recommended to use international activities, events, such as the China International Camping Conference, the International Tropical Agricultural Winter Fair, and the Hainan Island International Regatta to enhance international influence.

\subsubsection{Product promotion and marketing innovation}

Zheng Lao brand papaya milk stalls in Kaohsiung, Taiwan, are well-known. Ma Yingjiu, Lian zhan, Li Jiaxin, $\mathrm{Hu} \mathrm{Gu}$, Zhang Yu, etc. have all visited this famous Taiwanese snack, papaya milk, which has invisibly produced an "authoritative effect" on traditional cuisine. Moreover, the boss did not increase the price because of the high popularity and large demand. When promoting products such as lotus tea, it is recommended to ask nutrition experts to endorse and create an authoritative effect of marketing. Through the extension of the industrial chain, farmers will increase their income and increase agricultural efficiency.

\subsection{Environmental protection and full use of resources}

\subsubsection{Cultivation of environmental awareness among operators and citizens}

Governments and enterprises should avoid blindly overexploiting resources and protect the environment while cultivating local farmers' ecological civilization awareness and environmental awareness; the government should build a provincial-level environmental education base to start from the children and strengthen public environmental education. The government should take measures to prevent operators from being over-capacity, overloaded reception and operation in order to make profits; Hainan should learn from Taiwan's environmental protection measures such as "garbage not falling", "strict waste sorting" and "garbage recycling" to further protect the green mountains and green waters in Hainan.

\subsubsection{Measures to avoid ecological damage from rural tourism planning}

To prevent problems before they occur, we must plan well the rural tourism development to avoid damage to the ecological environment. In order to avoid noise pollution, it is necessary to ban noise exceeding the standard and speeding vehicles in the scenic area. The traffic trunk line should not be located in the residential area. The buildings in the scenic spot should conform to the relevant national sound insulation design standards. Soundproof belts and green belts should be set up reasonably. Entertainment venues should adopt better sound absorbing materials and sound absorbing structures, and construction sites should pay attention to sound insulation measures ${ }^{[11] .}$ 3.4.3. Rural tourism design should consider how to avoid landscape pollution

When designing rural tourist spots, we should maintain local characteristics and create an ecological environment that is in harmony with the local culture. This will make the building such as B\&B special and the localization of the event venue. Recreational facilities are protected from being too 
luxurious to prevent landscape pollution caused by artificial landscapes, modern architecture and the village's own style.

\subsubsection{Promotion of waste recycling}

It is recommended to improve the waste treatment capacity, adhere to the concept of circular economy, and follow reduction. The " $3 \mathrm{R}$ " principle of reusing and recycling enables resource conservation, turning waste into treasure, and recycling useful waste. For example, rural areas use clean and renewable energy such as biogas; use waste sheets as rags; waste coconut shells can be used as decorations, etc., which will not only save resources but also add Hainan characteristics.

\section{Acknowledgement}

This research was financially supported by Hainan Philosophy and Social Sciences Planning Project Funds (NO. HNSK(YB)16-89) .

\section{References}

[1] Zhang Jiangzhu, Development and management of cultural and ecological tourism in Quanzhou, Fujian Normal University, pp.15, 2009.

[2] http://www.traveldaily.cn/article/97687.

[3] http://www.hainan.gov.cn/hn/yw/zwdt/tj/201707/t20170709_2366331.html.

[4] Zhu Yong, Strengthening brand building and developing rural tourism according to local conditions in Hainan, http://www.hkwb.net/news/content/2016-08/01/content_3007322.htm, Aug.1, 2016.

[5] Regulations on management of private homes in Taiwan, http:// wenku. baidu. com.

[6] Li Jing, Lin Jing, etc, Development of the B \& B Industry in Taiwan, The Guide of Science \& Education, vol.10, pp.154-156, 2015.

[7] He Yanlin. Enlightenment of leisure agriculture and rural tourism development in Taiwan, Agriculture and Technology, vol.33, No.6, pp.218-220, 2013.

[8] Outline of Hainan rural tourism master plan (2014-2020), http://www.visithainan.gov.cn/government/redianzhuanti/2014zt/hainanjkxcfz/jkfzyj/201411/t2 0141106_53385.htm, Nov.6, 2014.

[9] Gao Xiaolei, Rural tourism in Taiwan "in the third eye", http://paper.dzwww.com/dzrb/content/20140317/Articel12002MT.htm, March 17, 2014.

[10]Ge Man, Research on the development path of home stay in eco cultural tourism, Journal of Anhui Agricultual Sciences, vol.41, No.23, pp.684-9685, 2013.

[11] Xu Wenbing, Wu Chengtao, etc, Rural tourism ecological environment protection measures and comprehensive countermeasures, Journal of Fujian Forestry Science and Technology, vol.37, No. 3, pp.144-149, 2010. 